Original Research Article

\title{
Knowledge and attitudinal survey of drug promotional literature among second year undergraduate students: a questionnaire based study
}

\author{
Ratna Agrawal, Mahendra Kumar Jaiswal*, Sanat Kumar Sharma, Raj Sharma
}

Department of Pharmacology, Late Baliram Kashyap Memorial Government Medical College, Dimrapal, Jagdalpur, Chhattisgarh, India

Received: 14 September 2019 Accepted: 17 October 2019

\section{*Correspondence to: \\ Dr. Mahendra Kumar Jaiswal, Email: drmkjaiswal@ \\ yahoo.co.in}

Copyright: (C) the author(s), publisher and licensee Medip Academy. This is an openaccess article distributed under the terms of the Creative Commons Attribution NonCommercial License, which permits unrestricted noncommercial use, distribution, and reproduction in any medium, provided the original work is properly cited.

\begin{abstract}
Background: Promotion of drugs has been increased enormously with the advancement of technology and use of internet and media etc. Pharmaceutical manufacturers spend vast amount of money on promotion usually through medical representatives by providing printed advertisements. But, it has been seen that these printed advertisements are not up to the mark usually, they either overemphasize the efficacy or hide the safety profile for the sake of company's profit. All these promotional activities influence the prescribing pattern of doctors. So, the present study has been conducted to assess the knowledge and attitude of second year undergraduate students about promotional literature and to train them accordingly for improving the prescribing behaviour.

Methods: A questionnaire based study containing 9 questions was conducted in 110 second year undergraduate students after taking informed consent. Statistical analysis was done by using descriptive statistics by graph pad prism version 6.01.

Results: Among respondents 60 (61.2\%) were males and rest $38(38.8 \%)$ were females. $50(51 \%)$ of the respondents have chosen Indian pharmacopoeia as a trusted source of information followed by others. Most common factor affecting the prescribing attitude was reported as updates from clinical trials 49 (50\%) followed by prescriber's knowledge. Most important intervention taken to stop misleading drug promotional activities has been reported as formulation of strict regulation by the health care authorities against any misleading promotion.

Conclusions: Promotional activities by manufacturers influence the attitude and prescribing pattern of doctors. So, it is important to teach the students about their rational use by critically analysing it.
\end{abstract}

Keywords: Drug promotional literature, Organisation of pharmaceutical producers of India, Questionnaire based, Second year undergraduates

\section{INTRODUCTION}

According to WHO, drug promotion literature (DPL) is defined as "all informational and persuasive activities by manufacturers, the effect of which is to induce the prescription, supply, purchase and/or use of medicinal drugs." In developing countries sales representatives are frequently the only source of drug information where there may be as many as one representative for every five doctors. ${ }^{2}$ Doctors themselves report that they often use promotion as a source of information about new drugs. ${ }^{1}$ Doctors in private practice, or who graduated long ago report the highest use of promotion as a source of drug information. ${ }^{\text {}}$

Research suggests that doctors' attitudes to promotion vary, and do not necessarily match their behaviour. Their opinion differ on the value of sales representatives, on whether they should be banned during medical training, and on whether doctors are adequately trained to interact with them. ${ }^{1}$ Most doctors think information from pharmaceutical companies is biased, but many think it is useful. $^{1}$ Heavy promotion of new drugs leads to widespread prescribing and use before the safety profile 
of these products is fully understood. Newer, more expensive medicines displace older, less costly ones without any evidence of an improvement in therapeutic outcomes. ${ }^{3}$ One more problem with DPL is that printed advertisements do not meet regulations and guidelines in force in various countries. Neither self-regulatory systems nor review by journal editors provide effective control on drug advertising. ${ }^{1}$

It has been seen that these DPL affect the attitudes of trainee doctors and their prescribing behaviour, so it is very important to educate them about critical appraisal of promotions to change their attitude for improvement of prescribing skills. Keeping this in mind, the present study has been conducted on second year undergraduate students to evaluate their existing knowledge about DPL and to educate them to deal with medical representatives (MR) and critically appraise any given DPL properly.

\section{METHODS}

This questionnaire based study was conducted in the Department of Pharmacology, Late Baliram Kashyap Memorial Government Medical College, Jagdalpur, Chhattisgarh during the month of August 2019.

After taking the signed informed consent, a pre-validated questionnaire was distributed to 110 second year MBBS students, of which 98 students responded. The purpose of the study was explained to the students and those who were not willing to take part in the study were excluded. ${ }^{4}$

The questionnaire consisted of 9 questions pertaining to the demographic profile of the students and their knowledge regarding drug promotional literature. The questions were single best answer type and true/ false type. The questionnaire was adapted from the similar study conducted earlier with some modifications. ${ }^{5}$ Ethical committee approval was obtained from the Institutional Ethics Committee, prior to the commencement of the study.

\section{Statistical analysis}

The filled questionnaire feedbacks were collected from the students and data were analysed using descriptive statistics by graph pad prism version 6.01. Results were presented as counts and percentage.

\section{RESULTS}

The questionnaire was given to total 110 second year undergraduate students, of which 98 responded. Among respondents $60(61.2 \%)$ were males and rest $38(38.8 \%)$ were females. The age range was between 19 to 25 years. $50(51 \%)$ of the respondents have chosen Indian pharmacopoeia as a trusted source of information followed by drug reference guides, textbooks and journals as depicted in Figure 1.

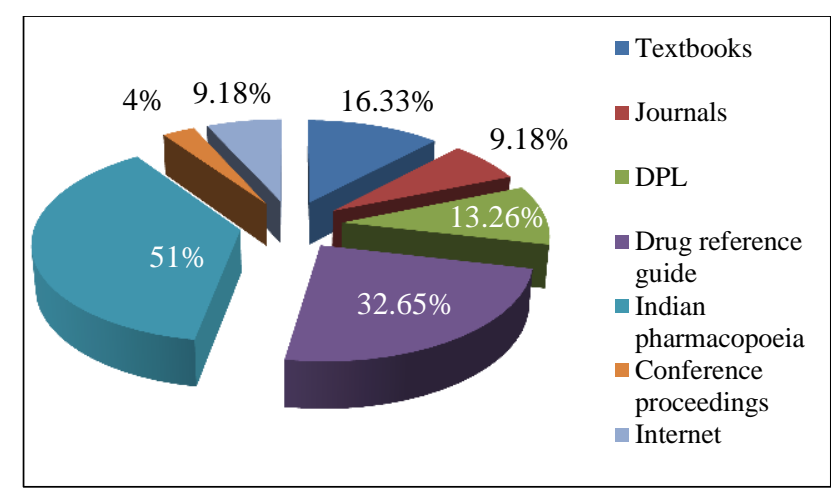

Figure 1: Source of information for prescribing the drugs.

Most common factor affecting the prescribing attitude was selected as updates from clinical trials 49(50\%) followed by prescriber's knowledge and others as shown in Figure 2.

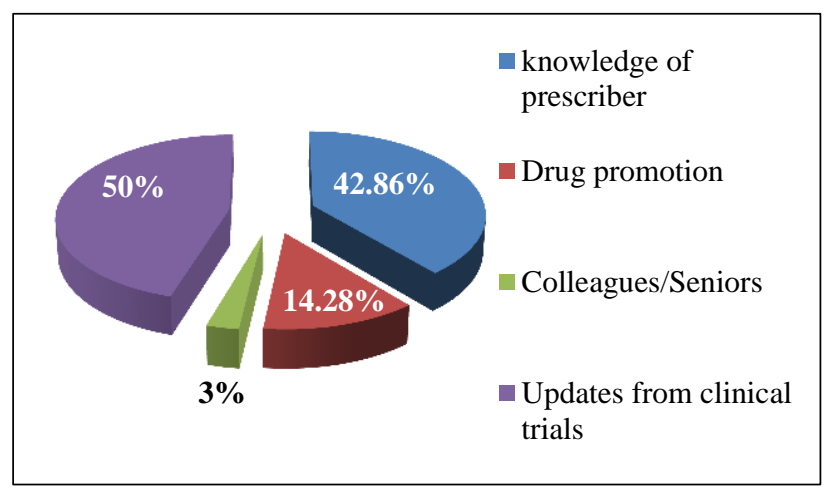

Figure 2: Factors affecting prescribing.

The most important factor a prescriber should consider while prescribing was safety/ efficacy according to most $79(80.6 \%)$ of the respondents followed by cost 17 (17.35\%) and local availability of the drug 12 (12.24\%).

Majority of the respondents $54(55.1 \%)$ believe that promotion of drug using internet or other media leads to self-medication and patient doesn't go to healthcare professional for his illness, while 26 (26.53\%) respondents believe that it provides information about various drugs which increase the patient compliance and final outcome and rest $20(20.41 \%)$ stated that patient draws inappropriate conclusion about the drugs.

Most of the respondent's opinion regarding the quality of information provided by medical representatives and advertisements was that drug information is biased and too commercial as presented in Figure 3.

Most important intervention can be taken to stop misleading drug promotional activities was stated by respondents as formulation of strict regulation by the health care authorities against any misleading promotion $73(74.49 \%)$, followed by educating the prescribers about 
drug promotional activities $43(43.88 \%)$ and involvement of media against unethical drug promotion $6(6.12 \%)$. Most common measures to be taken to reduce the influence of drug promotion on prescribing practices chosen by respondents was creating policies and guidelines for drug promotion as presented in figure 4.

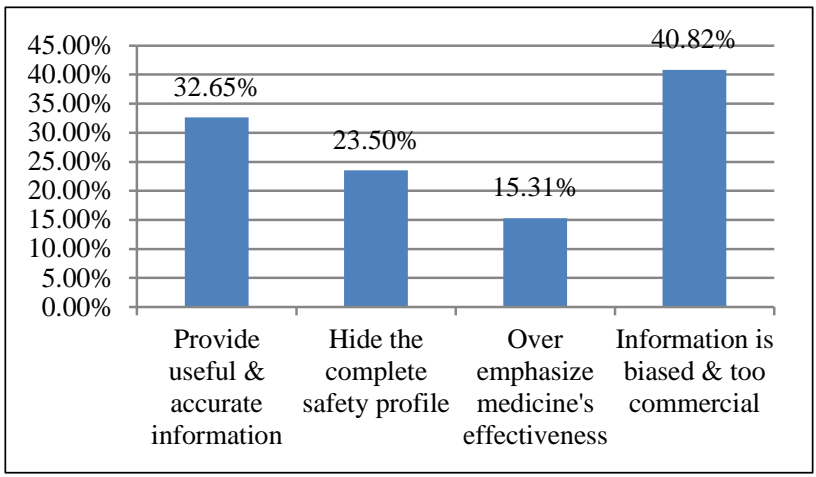

Figure 3: Opinion regarding quality of information provided by medical representatives.

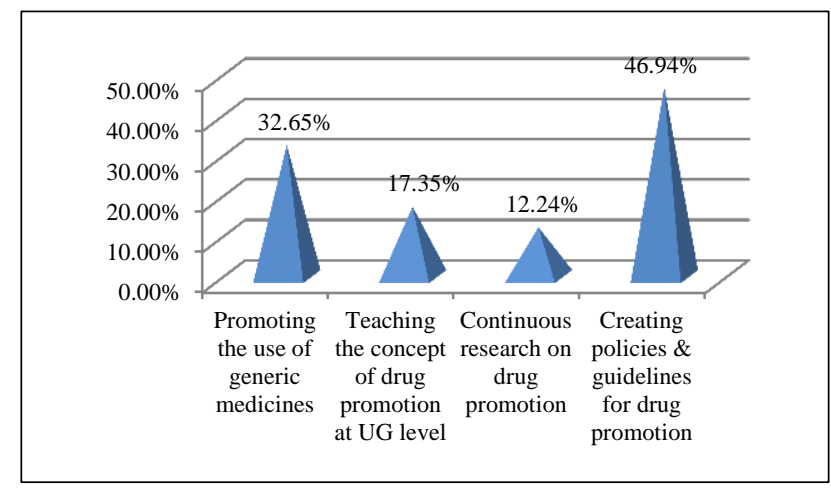

Figure 4: Measures to be taken to reduce the influence of drug promotion on prescribing.

The responses of students regarding the various activities done by medical representatives and manufacturer's for promotion of drug has been presented in table 1 and 2 .

Table 1: Opinion regarding drug promotion using medical representatives.

\begin{tabular}{|llll|}
\hline No. Responses & Yes & No \\
\hline $\mathbf{1}$ & $\begin{array}{l}\text { It updates prescriber's } \\
\text { knowledge about drugs }\end{array}$ & $\mathbf{N}(\mathbf{\%})$ & $\mathbf{N}(\mathbf{\%})$ \\
\hline $\mathbf{2}$ & $\begin{array}{l}\text { It helps in rational } \\
\text { prescribing }\end{array}$ & $\begin{array}{l}61 \\
(62.24)\end{array}$ & $29(29.6)$ \\
\hline $\mathbf{3}$ & $\begin{array}{l}\text { Prescriber becomes } \\
\text { obliged after receiving } \\
\text { the benefits from the } \\
\text { manufacturers }\end{array}$ & $53(54)$ & $42(42.8)$ \\
\hline & $\begin{array}{l}\text { Manufacturer's } \\
\text { promote off label use of } \\
\text { some medicines to make } \\
\text { profit }\end{array}$ & $80(81.6)$ & $18(18.4)$ \\
\hline
\end{tabular}

Table 2: Opinion regarding ethical aspects of drug promotion by manufacturers.

\begin{tabular}{|lll|}
\hline Response & Yes & No \\
\hline $\begin{array}{l}\text { Conducting } \\
\text { conferences/CMEs for }\end{array}$ & N $(\%)$ \\
$\begin{array}{l}\text { promoting their products } \\
\text { Distributing free medicine } \\
\text { during every visit by MR or } \\
\text { during a medical camp }\end{array}$ & $60(71.4)$ & $28(28.6)$ \\
\hline $\begin{array}{l}\text { Giving margin/ percentage of } \\
\text { their profit to prescriber/ } \\
\text { pharmacist }\end{array}$ & $26(26.5)$ & $72(73.5)$ \\
$\begin{array}{l}\text { Arranging tours/trips for } \\
\text { prescribers/pharmacists }\end{array}$ & $23(23.5)$ & $75(76.5)$ \\
\hline $\begin{array}{l}\text { Arranging private dinner } \\
\text { parties }\end{array}$ & $10(10.2)$ & $88(89.8)$ \\
\hline Gifts & $20(20.5)$ & $78(79.5)$ \\
\hline
\end{tabular}

\section{DISCUSSION}

The study has been conducted on second year undergraduate students to assess their knowledge regarding drug promotional literature. Most of the respondents in this study opined Indian pharmacopoeia and drug reference guide followed by textbooks are the most trusted source for getting knowledge about drugs for prescribing purposes although about $13.26 \%$ students also referred promotional literature as trusted source. The results of this study is in contrast to study conducted by Dixit et al, in which according to respondents most trusted source was chosen as textbooks and drug reference guides, but opinion regarding drug promotional literature is similar. ${ }^{5}$ As some of the students opined DPL as trusted source, they should be taught about the critical appraisal of these DPL, the mandatory information which should be included according to WHO criteria as many of them doesn't include complete safety profile and provide exaggerated information of efficacy and provide false claims.

Prescribing pattern is influenced by many factors like knowledge of the prescriber, seniors/colleagues prescribing behaviour, various updates from journals, clinical trials, CMEs and conferences and even DPL influence prescribing pattern. Most of the respondents in this study has opined that updates from clinical trials are most important followed by knowledge of prescriber although $14.28 \%$ students told that it is DPL which affect the prescribing most. Study conducted by Dixit et al, showed most important factor influencing the prescribing is knowledge of the prescriber followed by drug promotion. ${ }^{5}$ It is utmost important to train the students regarding correct use of DPL as research clearly shows that doctors who report relying more on promotion as a source of information tend to prescribe less appropriately, prescribe more often and adopt new drugs more quickly. ${ }^{1}$ 
At present advertisement, media and internet became most powerful source for getting any information and is also available easily. The internet also creates a new marketplace for illegal activities such as the sale of unapproved new drugs or products marketed with fraudulent health claims. ${ }^{5}$ Pharmaceutical manufacturers also spend vast sums of money on promotion, including sales representatives, samples, advertisements in broadcast and print media and sponsorship of educational events and conferences. ${ }^{1}$ So, appropriate measures or some guidelines should be made by regulatory authorities to check the availability of such kind of DPL among public domain, because by referring them public may draw inappropriate conclusion about the drug leading to various health problems like development of resistance by antibiotics.

Regarding quality of information provided by medical representatives and advertisements about the drug, most of the respondents opined that the information they provide is biased and too commercial while $32.65 \%$ respondents think that the information they provide is useful and accurate. But, the students are needed to teach to differentiate between true information and fake information by giving them appropriate training about retrieving the correct information by using various trusted sources available.

For stopping the misleading drug promotion activities, most of the respondents' opinion was that the health care authorities should make strict regulations against this. For the same, Organisation of Pharmaceutical Producers of India (OPPI) was established in 1965, a premier association of research and innovation driven pharmaceutical companies in India and is also a scientific and professional body. ${ }^{6}$ From $1^{\text {st }}$ January, 2019, the “OPPI Code of Pharmaceutical Practices 2019" replaces the "OPPI Code of Pharmaceutical Marketing Practices 2012". ' OPPI Member Companies are committed to the ethical standards set out in this OPPI Code, but the final responsibility of implementation of the OPPI Code is a matter of self-regulation and self-discipline. ${ }^{6}$

Regarding drug promotion done by medical representatives, most of the respondents opined that it updates the prescriber's knowledge, helps in rational prescribing but manufacturers promote off label use of some drugs to make profit. So, the medical representatives should be trained properly, and manufacturers should comply with guidelines formed by OPPI. If promotion leads to better prescribing, more rational use of medications or improved cost effectiveness then there would be no concern, but heavy promotion of new drugs leads to widespread prescribing and use before the safety profile of these products are fully understood. Newer, more expensive medicines displace older, less costly ones without any evidence of an improvement in therapeutic outcomes.
Regarding the ethical aspects of distributing free samples of the drug and conducting CMEs for promotion of their products, most respondents think it ethical. The opinion of respondents about the same corroborates with the study conducted by Dixit et al. ${ }^{5}$ But, according to OPPI's guidelines, "free samples of a pharmaceutical product may be supplied to healthcare professionals directly or to persons duly authorised by them to or to receive such samples on their behalf in order to enhance patient care. Samples should not be resold or otherwise misused."6 and regarding conducting CMEs "When companies provide content to CME activities and programs, such material must be fair, balanced and objective, and designed to allow the expression of diverse theories and recognized opinions. Content must consist of medical, scientific or other information that can contribute to enhancing patient care". 6

\section{CONCLUSION}

There are both pros and cons of promoting the drug. If promoted rationally and critically analyzed by healthcare professionals by using authentic sources of information, same may lead to better prescribing, more rational use of drugs and improved cost effectiveness. But, if promoted irrationally or unethically will ultimately lead to poor healthcare delivery and more economical burden on society. So, it is utmost important to appropriately train the future medical graduates about use of drug promotional literature by changing their attitude towards it.

\section{ACKNOWLEDGEMENTS}

Authors are thankful to all the students who were enrolled in the study for their co-operation in conducting the study.

\section{Funding: No funding sources \\ Conflict of interest: None declared \\ Ethical approval: Not required}

\section{REFERENCES}

1. Norris $\mathrm{P}$, Herxheimer A, Lexchin J, Mansfield P. Drug promotion. The Netherlands; World Health Organization and Health Action International 2005. Available at: https://apps.who.int/medicinedocs/pdf/ s8109e/s8109e.pdf. Accessed on 30 August 2019.

2. Lexchin J. Deception by design: pharmaceutical promotion in the third world. Penang: Consumers Interational, 1995.

3. Lexchin J. Should doctors prescribe new drugs?. Int J Risk Saf Medi. 2002;15:213-22.

4. Agrawal R, Sharma SK, Jaiswal MK, Sharma R, Ali SS. Evaluation of knowledge, attitude and practice of self-medication among second year undergraduate students in Bastar Region: a questionnaire based study. Int J Basic Clin Pharmacol. 2019;8:817-20.

5. Dixit R, Patil P, Chandrashekar R, Madhuri S, Mane A. Drug promotional activities as a source of medical 
information and its influence on prescribing. Int $\mathrm{J}$ Pham Bio Sci. 2014;4(3):113-9.

6. OPPI code of Pharmaceutical practices 2019.Mumbai: Organization of Pharmaceutical Producers of India; December 2018. Available on: https://www.indiaoppi.com/sites/default/files/oppi code of pharmaceutical producers of India. Accessed on 23 August 2019.
7. Wazana A. Physicians and the pharmaceutical industry: is a gift ever just a gift?. JAMA. 2000;283(3):373-80.

Cite this article as: Agrawal R, Jaiswal MK, Sharma SK, Sharma R. Knowledge and attitudinal survey of drug promotional literature among second year undergraduate students: A questionnaire based study. Int J Basic Clin Pharmacol 2019;8:2548-52. 